\title{
Mobile Applications for COVID-19: A Scoping Review of the Initial Response in Canada
}

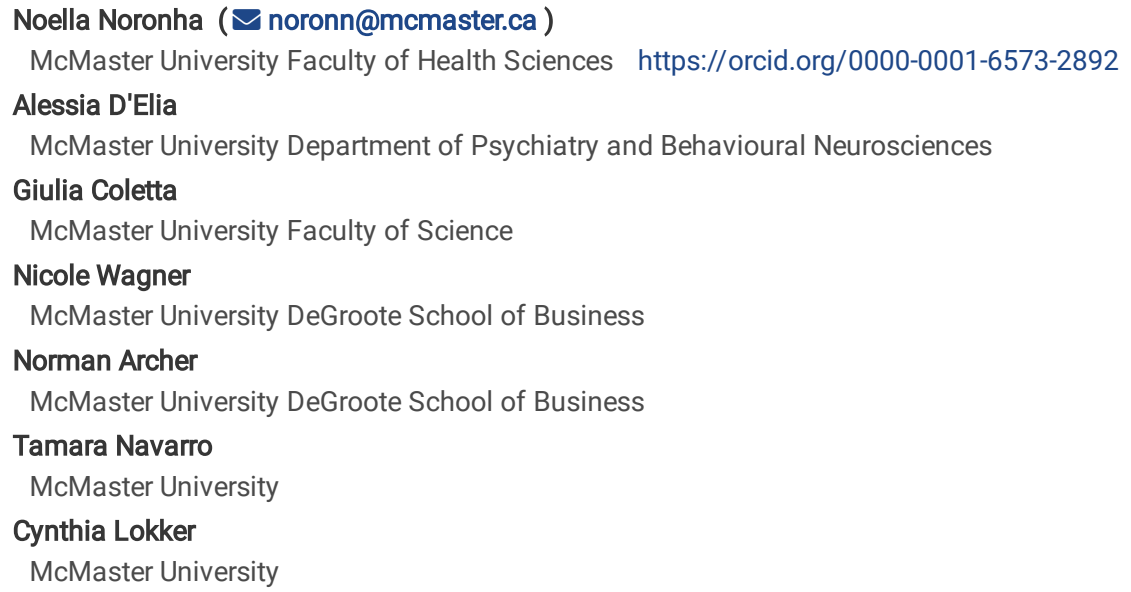




\section{Abstract}

Background: The rapid outbreak of Coronavirus diseases (COVID-19) originating in Wuhan, China, and the subsequent declaration of a state of "pandemic" on March 11, 2020 has necessitated a widespread global response to manage and control the transmission, spread and impact of COVID-19. Mobile technology has been leveraged in a number of ways to control the spread of COVID-19, including to support knowledge translation. Mobile applications are accessible, acceptable, easily adopted, and have the ability to support social distancing efforts. The following review assesses the mobile applications currently available to address COVID-19 and seeks existing studies in the literature that evaluate such applications.

Methods: 3 databases (Embase, Web of Science and PubMed), 2 application stores (GooglePlay and Apple's App Store) and google search engine were searched from inception until April 05, 2020 using key words and search strings to identify relevant apps and/or literature. Reviews of the obtained results were examined by two reviewers in double-blind nature and assessed for inclusion or exclusion.

Results: 36 studies, 72 websites and 312 mobile-based applications were identified through searches. 14 applications met the inclusion criteria and were analyzed. Additional eHealth tools identified through the search strategy were considered for supplemental analysis (including online dashboards and applications not available through application stores).

Conclusion: This review provides a brief assessment of the goals of applications addressing COVID-19, the types of approaches being used by these applications, and draws conclusions on the needs not being met by such application-based interventions. Innovation and collaboration between government, healthcare organizations and application developers is needed to address the identified gaps and facilitate the successful harnessing of mobile applications in the management of COVID-19.

\section{Background}

An outbreak of the 2019 novel Coronavirus diseases (COVID-19) that began in Wuhan, China has now escalated to a worldwide pandemic [1]. Individuals infected with COVID-19 experience mild to moderate respiratory illnesses, but often recover without requiring special treatment [2]. Symptoms of COVID-19 can include fever, cough, difficulty breathing and pneumonia in both lungs [1]. Older adults and those with underlying health disorders and medical problems such as cardiovascular and respiratory diseases, diabetes and cancer are more likely to have a more severe form of the illness [2]. COVID-19 spreads most commonly by human-to-human transmission through droplets of saliva or discharge from coughs and sneezes [2]. Around the globe, recommendations of social distancing for all citizens and self-isolation for those experiencing COVID-19 related symptoms have been implemented, with some regions resorting to government enforcement to uphold social distancing measures and prevent community transmission. Given what is known about transmission rates of coronaviruses, the COVID-19 pandemic may quickly overwhelm healthcare systems, leaving severely infected patients with deteriorating pulmonary conditions and no known effective forms of treatment [3].

Mobile health (mHealth) applications (apps) are software tools that can be installed on mobile devices, generally smartphones. With the increasing use of technology, apps have proven to be capable of broadly disseminating health knowledge and resources [4-8]. In an attempt to "flatten the curve" of the increasing number of COVID-19 cases, numerous apps have been created for COVID-19 to provide information to all civilians and subsequently relieve the pressure on healthcare systems. Apps have been designed to facilitate self-assessment at home, track statistics, and provide current updates. As the number of COVID-19 apps continues to grow rapidly, users need to be cognisant of the information being provided by critically appraising apps before downloading. Evidence has shown that fraudulent COVID-19 apps have been installing ransomware and spyware onto devices, resulting in Apple, Google and Amazon starting to block non-official Coronavirus apps from app stores, and denying any apps not from a "recognized institution" [9,10]. There are currently no studies that qualitatively assess the content of existing apps regarding COVID-19, despite reliance on these as part of a toolbox of strategies to support social distancing and personal decision-making to reduce the potential impact on overwhelmed clinical services. This review seeks to assess mobile apps created for COVID-19 available in Canada during the early onset of the pandemic. In order to do so, this review examines the landscape of mobile apps for COVID-19 available from literature or mobile app stores within the first few weeks of pandemic onset in Canada. This was done by providing a brief assessment of the goals of the apps and the approaches they use; where we consider the potential of such app-based interventions for supporting pandemic efforts. It is important to note that this paper was completed within the first few weeks of pandemic onset within Canada, being submitted for publication on April $6^{\text {th }}$ and the pandemic being declared in Canada on March $13^{\text {th }}$, therefore, it assesses the initial response of apps for COVID-19.

\section{Purpose}

The following study aims to:

(1) identify mobile apps and relevant literature related to mobile apps for COVID-19 available through Canadian application stores at the onset of the pandemic;

(2) characterize the focus or goals of the apps; and

(3) describe the apps in terms of accessibility, target age group, notification features, account capability, feedback surveys, language style and connectivity.

\section{Methods}

The Arksey and O'Malley framework was utilized with supplements for methodological improvements for scoping reviews [11-13]. Our methods also align with the PRISMA extension for Scoping Reviews (PRISMA-ScR) [14]. 
The research question was: What mobile apps for COVID-19 are available to date? Secondary research questions included, (a) What are the goals and features of the mHealth apps?; (b) Have these apps been studied?; and (c) Where are these apps available?

\section{Stage 2: Identifying Relevant Studies and Apps}

Searches for relevant apps were conducted in clinical databases, grey literature (websites) and mobile app stores (Apple Store and GooglePlay). Electronic databases including EMBASE, Web of Science and Pubmed, were searched from inception to April $5^{\text {th }}, 2020$. The search strategy (Table 1) was developed with advice from a science librarian and aimed to capture articles that included mobile apps for COVID-19. The search results were then reviewed to identify articles specifically targeting COVID-19. Searches of grey literature, described in Table 1, were completed through the Google Search Engine using key words "Coronavirus", "COVID-19", “Covid”, "SARS-CoV-2", “Corona Virus", and "Corona” crossed with specific terms such as "app”, "apps", "application” and "applications". Google Search Engine results were screened; only results pages recommended by Google as relevant were included in our search. Searches of the app stores, described in Table 1, were conducted using 6 key terms (i.e. Coronavirus, COVID-19, Covid, SARS-CoV-2, Corona Virus, Corona) to search for iPhone and Android apps in the Apple App Store and Google Play Store, respectively. These terms were included to capture any apps relevant to Coronavirus treatment, assessment, and diagnosis. The only restriction placed on apps was that they must be available in a Canadian app store and written in the English language (all other languages were excluded). Websites that did not discuss mobile apps were still considered for supplemental review if they were eHealth tools, and these results are reported separately from the main analysis of this paper. Such tools may include websites and dashboards that describe the COVID-19 pandemic.

Table 1. Key Search Terms for Web of Science, PubMed and Embase.

\begin{tabular}{|c|c|}
\hline Database & Search Terms \\
\hline $\begin{array}{l}\text { Web of } \\
\text { Science }\end{array}$ & $\begin{array}{l}\text { (mHealth or m-Health or mobile app* or cell* phone* or handheld device* or smartphone* or personal digital assist* or mobile } \\
\text { device* or tablet* or iPhone or iPad) AND TOPIC: (Coronavirus* OR Coronavirus disease* OR Coronavirus infection* OR SARS- } \\
\text { CoV-2 OR (wuhan and coronavirus)) }\end{array}$ \\
\hline Pubmed & $\begin{array}{l}((2019-n C o V \text { OR } 2019 n \text { CoV OR COVID-19 OR SARS-CoV-2 OR ((wuhan AND coronavirus) AND 2019/12[PDAT] } \\
\text { 2030[PDAT] }))) \text { AND ((m-health OR health OR mobile app* OR cell* phone* OR handheld device OR smartphone* OR personal } \\
\text { digital assist* OR mobile device* OR tablet* OR iphone OR ipad)) }\end{array}$ \\
\hline Embase & $\begin{array}{l}\text { (m-Health.mp. OR mHealth.mp. OR mobile app*.mp. OR mobile device*.mp. OR cell* phone*.mp. OR personal digital } \\
\text { assist*.mp. OR handheld device.mp. OR iPhone.mp. OR smartphone*.mp. OR mobile device*.mp. OR tablet*.mp. OR iPad.mp.) } \\
\text { AND ((wuhan AND coronavirus) Corona*.mp. OR Coronavirus*.mp. OR SARS-CoV-2.mp. OR SARS coronavirus/ OR COVID- } \\
\text { 19.mp.) }\end{array}$ \\
\hline $\begin{array}{l}\text { Google } \\
\text { Search } \\
\text { Engine }\end{array}$ & $\begin{array}{l}\text { Coronavirus, COVID-19, Covid, SARS-CoV-2, Corona Virus, Corona crossed with App, Application, Apps, Applications each. For } \\
\text { example: Coronavirus, Coronavirus App, Coronavirus Application, Coronavirus Apps, Coronavirus Applications. }\end{array}$ \\
\hline $\begin{array}{l}\text { GooglePlay } \\
\text { and Apple } \\
\text { Application } \\
\text { stores }\end{array}$ & Coronavirus, COVID-19, Covid, SARS-CoV-2, Corona Virus, and Corona \\
\hline
\end{tabular}

Stage 3: Study and app selection

Articles and apps identified through the search strategies were screened according to the following inclusion and exclusion criteria. The inclusion criteria included any citations pertaining to COVID-19, apps on mobile phones from 2019-present, and any apps that were available for download through a Canadian app store (For example: Apple's App store in Canada). The exclusion criteria were mobile apps that: (1) targeted persons with any disease other than COVID-19 (e.g., diabetes) even if they referred to other diseases within the coronavirus family of diseases (e.g., Severe Acute Respiratory Syndrome or SARS); (2) discuss the transmission, the management of symptoms, or the recommended treatment of conditions/diseases/illnesses other than COVID-19; and (3) apps not related to COVID-19. Any apps that were prototypes, not complete, or not available in an application store were excluded due to the potential for spyware, malware, and viruses that can be transmitted through mobile apps when downloaded from sources other than the app stores.

Citations retrieved from each search strategy were imported into an Excel spreadsheet, in order to review titles and abstracts for inclusion or exclusion. Two authors (NN and AD) first completed a calibration screen of 10 articles, deciding whether to include articles based on the following questions: (1) Does this article target COVID-19? and (2) Does the article refer to or include COVID-19 apps? If both screeners responded "yes" to both questions, the full text of the article was included in the full-text review screening (phase 2). If there was a discrepancy between the reviewers or decisions on any article, these articles were reviewed by a third reviewer (GC) and discussed to achieve consensus. Both screeners independently and blindly screened the titles and abstracts, then reviewed unblinded for any discrepancies. For GooglePlay or Apple Store search results, identified apps were screened in duplicate using the same inclusion and exclusion criteria as for the scientific literature. Any discrepancies in agreement were reviewed with a third reviewer (GC) and discussed to achieve consensus.

\section{Stage 4: Charting the data}

The following data were extracted from included articles, abstracts, and apps. Two reviewers (NN and AD) piloted data extraction, and then reviewed the data together. For searches of the app stores two reviewers (NN and AD) reviewed inclusion decisions collectively and extracted data independently based on predetermined criteria. All extracted data were verified by the other author (NN and AD). Mobile apps were examined for app features such as age rating, notification features, account capability, feedback surveys, and language style (Table 2). Features of the app that were specific to COVID-19 were extracted (Table 3). Grey literature searches using the Google Search engine were conducted to capture apps discussed in articles or news itemsthese searches 
identified apps, but also identified other eHealth tools, such as websites and dashboards. These items were examined for COVID-19 specific characteristics, and the results can be found in a supplementary table as these items did not meet criteria for the main analysis (Appendix A).

\section{Stage 5: Collating, summarizing and reporting the result}

Extracted information about articles and apps were summarized and assessed to identify themes and gaps. General and COVID-19 specific characteristics were assessed for each app (Table 2 and 3, respectively), and descriptions of each app were generated (Table 4).

\section{Results}

\section{Summary of Search Results}

Searches of EMBASE, Web of Science, and PubMed databases identified 34 articles. Of these 34 articles, 0 met inclusion criteria for the full-text review phase. Searches of grey literature yielded 72 web-based sites and popular articles; and 2 apps were identified as relevant through a popular article [15]. Searches of app stores identified 166 mobile apps. After de-duplication, 123 original apps were screened for inclusion. 14 apps met inclusion criteria and were eligible for data extraction, all applications were retrieved from the grey literature search exclusively. Major reasons for exclusions of apps were: 18.5\% ( $\mathrm{N}=22$ ) apps were related to business ventures (example: a Pizza shop called Pizzeria Corona), 6.72\% ( $\mathrm{N}=8$ ) were related to education (example: releasing COVID-19 related announcements), and 13.4\% ( $\mathrm{N}=16)$ were related to entertainment (for example, games). Other reasons for exclusion included fitness apps ( $\mathrm{N}=1)$, general apps that provided COVID-19 updates ( $\mathrm{N}=6)$ (e.g., apps that provided users with updates to services related to COVID-19 but whose focus was not COVID-19), lifestyle apps (e.g., Corona Community application) ( $\mathrm{N}=9$ ), apps discussing a different condition ( $\mathrm{N}=2)$, navigation apps $(\mathrm{N}=1)$, apps not available in English $(\mathrm{N}=38)$, social networking apps $(\mathrm{N}=3)$ and research-related apps $(\mathrm{N}=3)$.

\section{App Characteristics}

The general characteristics of the 14 apps are summarized in Table 2; all were free or had a free option, $71 \%(n=10)$ targeted a general audience including individuals with symptoms of COVID-19, $7 \%(n=1)$ were designed specifically for medical professionals, and $14 \%(n=2)$ were designed for general and medical professionals. The majority of apps were co-created with government organizations, followed by independent commercial organizations. Of the 14 apps, $35 \%$ $(n=5)$ were rated $4.0-4.9$ (out of 5$)$ by users, with $7 \%(n=1)$ receiving $5.0,21 \%(n=3)$ receiving 3.9 or below and $35 \%(n=5)$ having no available ratings. $14 \%$ $(n=2)$ had over 1000 reviews and $42 \%(n=6)$ had no reviews, while the remaining $42 \%(n=6)$ apps had between $1-99$ reviews. The apps included live updates; $14 \%(n=2)$ had the ability to notify health care providers and $71 \%(n=10)$ had news updates/statistics. Many apps were created in collaboration with $>1$ country, with $42 \%(n=6)$ of the included apps being created in North America. COVID-19 specific characteristics were integrated into the apps and summarized (Table 2). The apps had features for symptom management $(28 \%, \mathrm{n}=4)$ and symptom assessment $(57 \%, \mathrm{n}=8)$, and included resources such as the location of testing centres $(42 \%, n=6)$, preventative measures $(35 \%, n=5)$, regional/federal guidelines $(14 \%, n=2)$, specific instructions for those at greatest risk ( $14 \%, n=2)$, and physical distancing $(21 \%, n=3)$. Of the 14 apps, $28 \%(n=4)$ had a coronavirus "tracking feature", three had a live chat room feature, and $14 \%$ ( $n=2)$ had training resources for clinicians. A summary of the described features of these apps can be found in Table 2 and Table 3 . The main purposes of each app are provided in Table 4.

Table 2. General Application Characteristics, N=14, N (\%). 


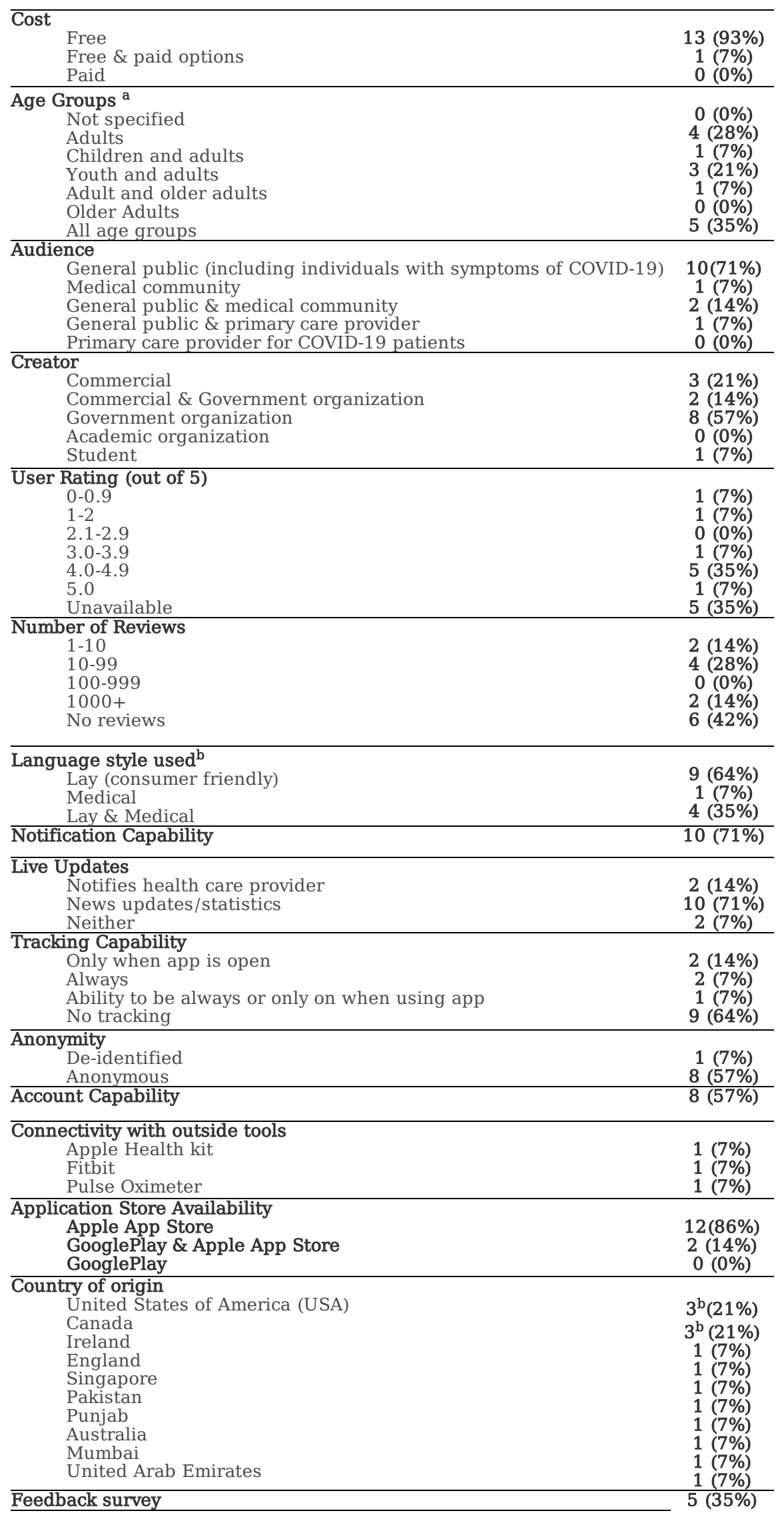

a Age Groups. Children: <18 years of age, Youth: 18-24, Adults: 25-64, Older Adults: 65+.

$\mathrm{b}$ One app was a joint development between the United States of America and Canada; this app has been added to both countries within this category. 


\begin{tabular}{ll}
\hline Symptom management & $\mathbf{4}(\mathbf{2 8} \%)$ \\
$\begin{array}{l}\text { Symptom assessment } \\
\text { Resource information in app }\end{array}$ & $8(57 \%)$ \\
Testing centres & $6(42 \%)$ \\
Preventative measures & $5(35 \%)$ \\
Regional/federal guidelines & $2(14 \%)$ \\
Those at higher risk & $2(14 \%)$ \\
Physical distancing & $3(21 \%)$ \\
Source of information supporting app & \\
Not specified & $2(14 \%)$ \\
Research evidence & $\mathbf{0 ( 0 \% )}$ \\
Professional experience & $2(14 \%)$ \\
Personal experiences or stories & $\mathbf{0 ( 0 \% )}$ \\
National guidelines & $\mathbf{2 ( 1 4 \% )}$ \\
Coronavirus tracking feature & $\mathbf{4 ( 2 8 \% )}$ \\
Live chat room & $\mathbf{3 ( 2 1 \% )}$ \\
Training resources for clinicians & $2(\mathbf{1 4} \%)$ \\
Frequently Asked Questions (FAQ) forum & $\mathbf{5 ( 3 5 \% )}$ \\
\hline
\end{tabular}

Table 4. Reported purposes of COVID-19 applications

\begin{tabular}{|c|c|}
\hline Mobile Application & Reported Purpose \\
\hline $\begin{array}{l}\text { HealthLynked COVID-19 } \\
\text { Tracker [16] }\end{array}$ & $\begin{array}{l}\text { Improving healthcare for everyone by connecting patients, doctors } \\
\text { and health care data around the world. }\end{array}$ \\
\hline \begin{tabular}{|l} 
HSE COVID-19 [17] \\
\end{tabular} & $\begin{array}{l}\text { A monitoring app for patients who have mild to moderate symptoms } \\
\text { and are in self-isolation. An alternative to visiting the hospital, ability } \\
\text { to be monitored remotely. }\end{array}$ \\
\hline \begin{tabular}{|l} 
BC Covid-19 Support [18] \\
\end{tabular} & $\begin{array}{l}\text { Developed by the BC Ministry of Health in partnership with Thrive } \\
\text { Health, the app provides latest updates and recommendations from } \\
\text { trusted experts. Helps to coordinate the provincial response to } \\
\text { COVID-19. }\end{array}$ \\
\hline $\begin{array}{l}\text { PatientSphere for COVID19 } \\
\text { [19] }\end{array}$ & $\begin{array}{l}\text { Created to allow patients to control their medical data and monetize } \\
\text { the information (sharing with researchers). }\end{array}$ \\
\hline \begin{tabular}{|l} 
Trace Together [20] \\
\end{tabular} & $\begin{array}{l}\text { Community driven contact tracing app to help stop the spread of } \\
\text { COVID-19. }\end{array}$ \\
\hline $\begin{array}{l}\text { Osler Covid Learning Centre } \\
{[21]}\end{array}$ & $\begin{array}{l}\text { Resource app that is designed to support nurses, doctors, paramedics } \\
\text { and allied health professionals to learn and refresh their } \\
\text { skills/knowledge, providing podcasts, videos, and training modules. }\end{array}$ \\
\hline \begin{tabular}{|l|} 
Canada COVID-19 [22] \\
\end{tabular} & $\begin{array}{l}\text { Developed by the BC Ministry of Health in partnership with Thrive } \\
\text { Health, this app was expanded for all Canadians. This app helps to } \\
\text { determine care plans and next steps if any symptoms appear, } \\
\text { providing personalized recommendations based on personal risk } \\
\text { factors. This app gives updates on the COVID-19 situation in Canada, } \\
\text { and important news from the Ministry of Health, in accordance to } \\
\text { current guidelines. }\end{array}$ \\
\hline CoviD-19! [23] & $\begin{array}{l}\text { This a app gives basic information on COVID-19, how to prevent it, and } \\
\text { how to defend against it. Provides up-to-date information about the } \\
\text { world. Features a map with the occurrence of COVID-19 which allows } \\
\text { you to view specific information about a location of interest. }\end{array}$ \\
\hline \begin{tabular}{|l} 
COVID-19 Gov PK [24] \\
\end{tabular} & $\begin{array}{l}\text { This app includes dashboards for information on cases by state in } \\
\text { Pakistan. This app provides pop-up notifications to remind individuals } \\
\text { of personal hygiene. Chatbot services and awareness videos are } \\
\text { provided in order to limit spread of COVID-19. }\end{array}$ \\
\hline \begin{tabular}{|l} 
COVA Punjab [25] \\
\end{tabular} & $\begin{array}{l}\text { Provides preventative care information, emergency and hotline } \\
\text { details. This app has been developed by the Government of Punjab to } \\
\text { provide government advisories, a dashboard to track the evolving } \\
\text { COVID- } 19 \text { situation for Punjab, India and the world. This app includes } \\
\text { a symptom checker for self-screening, raises awareness, and provides } \\
\text { information on travelling instructions, prevention products, and } \\
\text { healthcare resources. The app includes a FAQ section and call } \\
\text { support. }\end{array}$ \\
\hline Coronavirus Australia [26] & $\begin{array}{l}\text { Provides up to date information and advice for Coronavirus and } \\
\text { preventing its spread. Quick snap-shots of the current status of } \\
\text { Australia. Symptom-checking functionality for oneself or others. This } \\
\text { app includes relevant contact information and updates from the } \\
\text { Australian government. Push notifications are provided for urgent } \\
\text { updates. }\end{array}$ \\
\hline BMC Combat Covid19 [27] & $\begin{array}{l}\text { Notes location and provides information to track health status to the } \\
\text { Municipal Corporation of Greater Mumbai. }\end{array}$ \\
\hline CoronaFACTS [28] & $\begin{array}{l}\text { Informational service informed by physicians, providing information } \\
\text { on coronavirus globally. This app incorporates an interactive map to } \\
\text { show the evolving situation, and global newsfeeds that can be filtered } \\
\text { in order to find country-specific data. }\end{array}$ \\
\hline TraceCOVID [29] & $\begin{array}{l}\text { Allows users to detect other devices in close proximity with the same } \\
\text { app installed, and share proximity data with it If one of the users of } \\
\text { the app becomes infected with coviD-19, official authorities will } \\
\text { request the infected user to upload the list close contacts stored on } \\
\text { his or her device obtained through the app. }\end{array}$ \\
\hline
\end{tabular}

\section{Discussion}

While this scoping review found that rapidly increasing numbers of mobile apps are being created for the evolving COVID-19 outbreak, it is no surprise that evidence-based assessments of these apps do not currently exist. The rapid growth of the commercial market and need for COVID-19 apps has outpaced a standard of improvement for content and functionality of these mobile apps, resulting in an overaccumulation of COVID-19 apps with little evidence of effectiveness despite their availability for public use.

All 14 of the mobile apps appeared to have a singular focus, being either symptom management/assessment, news updates/statistic tracker, or an information sharing/training app; none comprehensively include a full range of features. 
Current capabilities for sharing news, statistics, and live updates of COVID-19 through the included apps limit user customization, meaning that the app may share information that is irrelevant to the user's geographic location or provide notification that are not relevant regardless of whether the user wants them. $71 \%$ have live news and statistics communicated through the app, nearly all of which impart global, rather than local or user-selected information. Several of the apps included some type of territorial filtering but remained broad; for example, Canada COVID-19 allowed for province filtering, but does not support specific data for certain cities and towns [22]. BC COVID-19 is specific with features and content for British Columbians but still remains broad in terms of city filtering, remaining as a general tool for the entire province [18]. While many of the apps (77\%) had the ability to convey news and statistics, these apps did not frequently provide notifications to users for live updates. Research has shown that mobile app notification can be a useful tool when used at the appropriate frequency with a concise message [30]. It is important for future apps related to COVID-19 to consider personalized notification features to increase app interaction and dissemination of desired content.

Research has shown that apps can be successful in improving symptom management and tracking, specifically apps that allowed clinicians to provide input [31]. One app, HSE COVID-19, had the capability to document users' in-home isolation and synchronize activity data with Apple's Health Kit, Fitbit, and a pulse oximeter [17]. These results are then shared with clinicians who remotely monitor patients. Measuring a patient's oxygen saturation, symptoms and activity allows clinicians to review a patient's condition in self-isolation, while ultimately avoiding a hospital visit until absolutely necessary, therefore reducing the risk of spreading or contracting the virus by reducing the number of unnecessary visits. This feature may be beneficial for future app developers to consider. Of interest is the fact that only two of the six included apps had feedback surveys, despite research which indicates feedback is a valuable resource for quality improvement of mobile apps [32].

One of the apps, Coronavirus Australia, had the ability to document registered isolation [26]. The Government of Australia used this information to better understand the experience of those in isolation, to create a safeguard for isolated individuals, and to allow public health to conduct appropriate analysis and research. Personal information was collected, including name, age, and geographical location to allow the government to obtain timely and accurate infection rates. No personal information was disclosed to parties overseas, and was instead stored on servers within Australia. While this app did not allow tracking of the participant in isolation to be shared with other individuals on the app, it allowed public health to remain updated on the patient's current status through documentation of symptoms. It also allowed public health to confirm that self-isolation was being followed by monitoring individuals' geographical location and ensuring it matched the selected location of isolation on the app. Analysts interpreting this data should do so cautiously, as the correct tracking would require for the subject to carry their mobile device with them at all times, and therefore this function may lead to inaccurate mapping

Only one of the included apps, OSLER Covid Learning Centre, was strictly a resource app for supporting health care providers at William Osler Hospital in Brampton, Ontario [21]. The app hosted a learning centre focused on COVID-19 related topics such as techniques on non-invasive ventilation and coventilation of multiple patients. The app shared updated World Health Organization (WHO) situation reports, the Cochrane library collection for critical care management and infection control, and videos and podcasts related to COVID-19. The use of apps for education of hospital staff has the potential to share information in an innovative and engaging format that enables users to learn at their own speed [33] and is a good approach in an evolving situation. Given the current recommendation of self-isolation and social distancing, a mobile app would allow for health care providers in various fields (for example, home nurses, personal support workers, and mobile phlebotomists) to convene on health topics and changes to protocol without potentially perpetuating the spread of COVID-19.

Social media is a popular source for news consumption, with users claiming the value of sharing news in real-time and exposure to a wider range of topics $[34,35]$. Popular mobile apps such as WhatsApp, TikTok, Facebook, Instagram, and Twitter have been sharing COVID-19 knowledge by creating Information Centres available through their apps. These Information Centres include updates from health organizations, tips on self-isolation, and resources for sharing with loved ones. The information shared on each of these platforms can be specific to the geographical location of the user and reflects information from the recognized Health Organization serving their area. Canadian Facebook users can review COVID-19 information shared by the Government of Canada, found on Canada.ca/coronavirus. WhatsApp has been commissioned by the WHO to begin facilitating information sharing on COVID-19; users can send messages to a number specific to their area to subscribe for COVID-19 updates, reports and statistics in real-time [36]. The strategies used by popular social media support the growing perspective that social media platforms are central to the way people experience news [34,35].

Many pre-existing apps have also begun including COVID-19 related features, modifying their apps to fit the needs of their users during the pandemic. Headspace, a self-help app used for tackling challenges such as anxiety, relationships and sleeplessness, began offering free guided meditations and exercises to all employers and employees to compassionately support teams through the stress and anxiety of COVID-19 [37].

While the development and use of apps could be critical in circulating information and minimizing the spread of disease by encouraging virtual engagement with clinical services, caution must be exercised when selecting which apps to download. Disguising themselves as sources of information on the COVID-19 outbreak, some apps are installing malware and demanding special access once downloaded [15]. To address these fraudulent apps, and to curb the sharing of inaccurate information, the Apple Store and Google Play Store seem to be obscuring searches for "coronavirus", "covid-19" and other similar keywords $[9,10]$. Such searches have yielded "no results found" messages or have returned options from reputable sources such as the Centre for Disease Control and Prevention (CDC) app. Without any clinical validation of apps, users should be wary of sources of any COVID-19 information. Apps affiliated with ministries of health, government organizations, and academic institutions should be prioritized when searching for reliable mobile sources of information for COVID-19.

Further research should also evaluate web-based apps and online dashboards for tracking COVID-19. A number of dashboards are currently available which allow consumers to view the evolving global trajectory of COVID-19 by including confirmed and recovered cases, and deaths [38-43]. Many of these dashboards transform these data into charts and interactive maps to help consumers visualize these statistics and the distribution of cases. With the functionality to group country data and customize filters, these dashboards provide users the opportunity to put these data into a more local and personal context [38-43]. A majority of the dashboards identified through Google Search Engine include those which cite their data from the Coronavirus COVID-19 
Global Cases dashboard supported by the Center for Systems Science and Engineering at Johns Hopkins University [39], which itself cites the WHO, the CDC, the European Centre for Disease Prevention and Control, and other federal organizations worldwide. Dashboards have been proven to support the fight against infectious diseases by collating location to events in relationship to disease spread [44]. One hallmark example is the Cholera outbreak in Soho, London. In 1858, John Snow was able to complete hand-spatial analysis to determine that pumps supplying water were the source of Cholera outbreaks [45]. By analyzing the distribution of disease, dashboards have the potential to present the patterns of spread of COVID-19 in ways that may help minimize transmission. While dashboards, and websites were not targeted for inclusion within this paper, it is important to highlight all of the information sources available on mobile devices regarding the advancing COVID-19 crisis to illustrate the current environment of this field.

While this review did not include apps that were not available on an app store or in a language other than English, an app developed in Hangzhou City, Zhejiang, China [46] is worth highlighting. This health status app displays colours of either green, yellow, or red to indicate the current health status of the user [46]. The colours are allocated based on information reported by the individual, including their current health status, travel history, and previous exposure to highly affected areas such as Wuhan, China. Those with a red or yellow code are required to undergo quarantine, while anyone with assigned green can continue going to work. These unified health code systems are promoted throughout China and checked frequently on public transportation and by safety officers to ensure compliance with quarantine regulations to maintain the safety of other civilians [46]. While such a strategy could look promising in maintaining quarantine regulations, it is important to consider that these codes are sensitive to users' input, and that these answers require no medical verification [46].

Lastly, the SARS-2003 outbreak had public health recommendations similar to those now being practiced for COVID-19, including wearing face masks and social distancing [47]. Two unique citations obtained through a grey literature search provided insight on apps modelled on the SARS-2003 outbreak (Table 6, Appendix B). One of the strategies implemented in Singapore during the SARS-2003 outbreak involved electronic tracking of individuals entering public hospitals. Staff and visitors were required to wear credit-card sized radio frequency identification (RFID) cards, and these records were saved by the hospital for 20 days [48]. If an individual became infected, health officials would examine who had been in contact with them based on RFID tracking records [48]. Today, mobile apps in South Korea, such as Corona 100m, have used this strategy through Bluetooth technology [49]. Participants no longer require credit-card sized recognition cards but can anonymously be tracked through their mobile devices. The information is anonymous to users of the apps; that is, users are able to see where de-identified individuals with COVID-19 have been while government health officials and mobile developers are able to identify who each user is. Further, when a patient is recognized as infected with COVID-19, the Ministry of Health and Welfare in South Korea examines the apps to ensure that the patient stays in quarantine and follows rules of contact [50]. In addition, TraceCovid, one of the included apps in this study, implemented similar strategies utilizing Bluetooth frequencies to identify individuals who has crossed paths. All users who have downloaded the app have their paths and contact with other individuals traced and are able to share this information with Government authority if identified as COVID-19 positive. However, apps for the COVID-19 outbreak largely fail to consider the eHealth technologies that were implemented during the SARS-2003 outbreak. SARS-2003 apps wirelessly transmitted symptoms to health or infectious disease centres and allowed for remote monitoring of patients, communicating through Short Message Service (SMS) notifications on nearby SARS exposure for users who choose to share their phone location [47]. Given the 17-year gap, apps created for COVID-19 should look to past successes and failures of SARS-2003, creating apps that are multifaceted and able to combine all features of tracking, notification, statistics, updates, and symptom management.

mHealth apps remain an affordable, portable, and cost-effective strategy in delivering healthcare [51]. They also constitute an excellent platform for data collection. Some apps, such as Corona-care, allows healthcare workers to access and track patient symptoms remotely, while also collecting longitudinal data for research institutions. This app is accessible to patients who may have COVID-19 and have been seen by a clinician regarding their condition. Another application called Castor COVID-19 was developed for research purposes to collect population level data on COVID-19 by asking participants to report symptoms daily. As these apps can only be downloaded in a research context, they were not included for data extraction, but they were still described within the discussion to highlight the mobile app landscape during COVID-19. While helpful in supporting research efforts and in collecting data for healthcare purposes, it is important to consider privacy, security and additional expenses to the users of these apps, as well as the effects of these factors on adoption rates. In continuous location tracking apps, similar to TraceCovid and Corona100m, users agree to share information by consenting to a location tracking request [15]. Research has shown that $1 / 5^{\text {th }}$ of cell phone users have turned off location tracking features on their phone, citing worries of privacy invasion $[40,50]$. Overtime, users have been found to become comfortable sharing private information with larger corporations when a long-term business relationship between users and services providers has been established [52]. Given that many apps created for COVID-19 are created by government organizations, users may be more comfortable sharing private information. However, privacy issues can remain constrained regardless of the business relationship, with users choosing not to share their location when in a sensitive area that they prefer not to be disclosed, such as place of work or home address. Security concerns pose another adoption constraint, worrying users of potential attacks through malware infection such as viruses [53]. It has been suggested that all mobile apps available on application stores be created in accordance with standard guidelines to ensure that security procedures are put into place [54]. While the evolving pandemic of COVID-19 moved quickly, developers should still be held to a high standard when creating apps to ensure privacy and security measures are undertaken. The overall quality, security and privacy concerns, and additional costs related to the applications should also be taken into account. For example, apps with location tracking function in the background present a challenge in terms of data usage and internet access. When developing apps, data consumption and the reliance upon internet access should be considered in order to reduce user monetary burden and maximize the level of access to pertinent information. The application development process could address such concerns though involvement of end-users in order to incorporate the consumer perspective adequately.

\section{Limitations}

This scoping review has several limitations. Firstly, the review of the grey literature was limited to a search of app stores and websites, and did not capture dissertations, unpublished reports, or conference abstracts, though the availability and abundance of such material is unlikely given the recency of the onset 
of the COVID-19 pandemic. Further, the apps included from clinical databases were those in published trials or articles concerning mobile apps for COVID-19. A second limitation of this review is the breadth of the eHealth tools analyzed. While there are other tools available to the public with respect to this pandemic, this review focused exclusively on mobile apps. Thirdly, applications which covered a multitude of health concerns in addition to COVID-19 were not included in this analysis, as the aim of the study was to assess apps designed specifically for addressing COVID-19 rather than apps designed to respond to pandemics generally. For example, some apps provided information on a variety of health topics, such as heart disease, diabetes, and made extensions to also cover COVID-19 as a result of the current crisis. Additionally, this analysis is limited by the accuracy of the features reported by the application developers; that is, this analysis captures the capabilities reported by the app developer and does not reflect whether these features are accurate. Reasonable measures to confirm the accuracy of reported functions were taken by all reviewers, however, it is possible that features such as "sending symptom data" to the relevant health or regulatory bodies may not have full functionality. Finally, in keeping with the objective to reflect a Canadian perspective of the mobile application landscape, this review systematically excluded grey literature and published work that was not in the English language and could not be accessed in Canadian application stores, meaning that some apps for COVID-19, notably those developed in countries who were faced with the virus earlier, are not included. In turn, this investigation is biased toward apps designed by English-speaking nations or developers, and those that can be accessed in Canada.

\section{Conclusions}

The impetus to create apps to provide mobile support in the wake of the COVID-19 pandemic has resulted in the development of different types of apps and eHealth solutions. However, further expansion is needed to create apps which host multiple helpful features in one place, supported by reliable statistics and updates. Strengthening of partnerships between academic and research institutions, healthcare, and government is needed in order to create apps that will serve to improve the quality of the information accessed by the public and bridge the gaps in healthcare widened by the current pandemic. This scoping review identifies the areas currently being addressed by apps for COVID-19 but also highlights a number of opportunities for improvement and innovation. Collaboration between key stakeholders will not only provide vital platforms to respond to the current crisis but also stimulate the development of infrastructure for future health challenges.

\section{List Of Abbreviations}

apps: applications

CDC: Centre for Disease Control and Prevention

COVID-19: 2019 novel Coronavirus disease

FAQ: Frequently Asked Questions

mHealth: mobile health

PRISMA-ScR: PRISMA for Scoping Reviews

SMS: Short Message Service

SARS: Severe Acute Respiratory Syndrome

WHO: World Health Organization

\section{Declarations}

\section{Ethics approval and consent to participate}

Not applicable.

\section{Availability of Data and Materials}

The datasets used and/or analysed in this study are available from the corresponding author on reasonable request.

\section{Consent for publication}

All authors consent for publication.

\section{Competing Interests}

No competing financial interests exist. All authors declare no conflicts of interest.

\section{Funding}

This research received no specific grant from any funding agency in the public, commercial or not-for-profit sectors.

\section{Author Contributions}


$\mathrm{NN}$ and $\mathrm{AD}$ conceived the study, participated in its design and all review steps. GC drafted the results section and corresponding text. NN, $A D$ contributed to the literature synthesis and led the writing of the final manuscript. NA, CL, and NW provided critical revision of the manuscript. All authors read and approved of the final manuscript.

\section{Acknowledgements}

We would like to thank Ms. Tamara Navarro for their expertise and support in the conception and development of the search strategies.

\section{References}

1. Gao Q, Hu Y, Dai Z, Xiao F, Wang J, Wu J. The Epidemiological Characteristics of 2019 Novel Coronavirus Diseases (COVID-19) in Jingmen, China. SSRN Electron J. 2020;

2. World Health Organization. Coronavirus. 2020 [Internet]. 2020. Available from: https://www.who.int/health-topics/coronavirus\#tab=tab_1

3. Chen Y, Liu Q, Guo D. Emerging coronaviruses: Genome structure, replication, and pathogenesis. Journal of Medical Virology. 2020.

4. Mobasheri MH, Johnston M, King D, Leff D, Thiruchelvam P, Darzi A. Smartphone breast applications - What's the evidence? Breast. 2014;

5. Azar KMJ, Lesser LI, Laing BY, Stephens J, Aurora MS, Burke LE, et al. Mobile applications for weight management: Theory-based content analysis. Am J Prev Med. 2013;

6. Grasaas E, Fegran L, Helseth S, Stinson J, Martinez S, Lalloo C, et al. Icancope with pain: Cultural adaptation and usability testing of a self-management app for adolescents with persistent pain in Norway. J Med Internet Res. 2019;

7. Bonoto BC, de Araújo VE, Godói IP, de Lemos LLP, Godman B, Bennie M, et al. Efficacy of Mobile Apps to Support the Care of Patients With Diabetes Mellitus: A Systematic Review and Meta-Analysis of Randomized Controlled Trials. JMIR mHealth uHealth. 2017;

8. D. L, P. W, F. L, J. E, J.A. S, Y.C. L. Mobile Apps for Individuals with Rheumatoid Arthritis: A Systematic Review. J Clin Rheumatol. 2019;

9. Musil S. Apple rejects coronavirus apps not from a "recognized institution," report says. 2020; Available from: https://www.cnet.com/news/applereportedly-rejecting-coronavirus-related-apps-not-from-recognized-institutions/

10. Sherr I. Apple, Google, Amazon block nonofficial coronavirus apps from app stor. 2020;

11. Arksey H, O'Malley L. Scoping studies: Towards a methodological framework. Int J Soc Res Methodol Theory Pract. 2005;

12. Daudt HML, Van Mossel C, Scott SJ. Enhancing the scoping study methodology: A large, inter-professional team's experience with Arksey and O'Malley's framework. BMC Medical Research Methodology. 2013.

13. Levac D, Colquhoun H, O’Brien KK. Scoping studies: advancing the methodology. Implement Sci. 2010;5(1):69.

14. Tricco AC, Lillie E, Zarin W, O'Brien KK, Colquhoun H, Levac D, et al. PRISMA extension for scoping reviews (PRISMA-ScR): Checklist and explanation. Annals of Internal Medicine. 2018.

15. Naughton J. Smartphones could help us track the coronavirus - but at what cost? 2020 Mar 21; Available from: https://www.theguardian.com/commentisfree/2020/mar/21/smartphones-could-help-track-coronavirus-but-at-what-cost

16. HealthLynked Corp. HEALTHLYNKED COVID-19 Tracker [Internet]. 2020. Available from: https://apps.apple.com/ca/app/healthlynked-covid-19tracker/id1500575377

17. patientMpower Ltd. HSE COVID-19 [Internet]. 2020. Available from: https://apps.apple.com/ie/app/hse-covid-19/id1502617117

18. Province of British Columbia. BC COVID-19 Support [Internet]. 2020. Available from: https://apps.apple.com/ca/app/bc-covid-19-support/id1502907052

19. Open Cancer Network. PatientSphere for COVID-19. 2020.

20. Government Technology Agency. TraceTogether [Internet]. 2020. Available from: https://apps.apple.com/sg/app/tracetogether/id1498276074

21. Osler Technology. Osler COVID Learning Centre [Internet]. 2020. Available from: https://apps.apple.com/au/app/osler-covid-learningcentre/id1504015523

22. Health Canada / Santé Canada. Canada COVID-19 [Internet]. 2020. Available from: https://apps.apple.com/ca/app/canada-covid-19/id1505010304

23. Nemocnice Milosrdnych bratri p.o. COVID-19! 2020.

24. National Information Technology Board. COVID-19 Gov PK. 2020.

25. Government of Punjab. COVA Punjab [Internet]. 2020. Available from: https://apps.apple.com/in/app/cova-punjab/id1501977319

26. Australian Department of Health. Coronavirus Australia [Internet]. 2020. Available from: https://apps.apple.com/au/app/coronavirusaustralia/id1503846231

27. Municipal Corporation of Greater Mumbai (MCGM). BMC Combat Covid [Internet]. 2020. Available from: https://apps.apple.com/in/app/bmc-combatcovid19/id1504083673

28. Trusted Medical LLC. CoronaFACTS. 2020.

29. Department of Health Abu Dhabi. TraceCOVID. 2020.

30. Pham XL, Nguyen TH, Hwang WY, Chen GD. Effects of push notifications on learner engagement in a mobile learning app. In: Proceedings - IEEE 16th International Conference on Advanced Learning Technologies, ICALT 2016. 2016.

31. Whitehead L, Seaton P. The effectiveness of self-management mobile phone and tablet apps in long-term condition management: A systematic review. Journal of Medical Internet Research. 2016. 
32. Scherr SA, Elberzhager F, Meyer S. Listen to Your Users - Quality Improvement of Mobile Apps Through Lightweight Feedback Analyses. In: Lecture Notes in Business Information Processing. 2019.

33. Khaddage F, Lattenman C. The future of mobile apps for teaching and learning. Handb Mob Learn. 2013;119-28.

34. Hermida A, Fletcher F, Korell D, Logan D. SHARE, LIKE, RECOMMEND: Decoding the social media news consumer. Journal Stud. 2012;

35. Nielsen RK, Schrøder KC. The Relative Importance of Social Media for Accessing, Finding, and Engaging with News. Digit Journal. 2014;

36. World Health Organization. WHO Health Alert brings COVID-19 facts to billions via WhatsApp. 2020 Mar 27; Available from: https://www.who.int/newsroom/feature-stories/detail/who-health-alert-brings-covid-19-facts-to-billions-via-whatsapp

37. Headspace. We're here for your workplace [Internet]. 2020 [cited 2020 Apr 2]. Available from: https://www.headspace.com/work/covid-19

38. Zimmermann R. Tracking Coronavirus COVID-19 [Internet]. [cited 2020 Mar 30]. Available from: https://app.developer.here.com/coronavirus/

39. Johns Hopkins University. Coronavirus COVID-19 Global Cases by the Centre for Systems Science and Engineering (CSSE) [Internet]. 2020. Available from: https://gisanddata.maps.arcgis.com/apps/opsdashboard/index.html\#/bda7594740fd40299423467b48e9ecf6

40. Titus Kipruto. COVID-19 tracker Dashboard [Internet]. [cited 2020 Mar 30]. Available from: https://titusbatson.com/covid-19-tracker/

41. Titus Kipruto. No Title [Internet]. 2020 [cited 2020 Mar 30]. Available from: https://titusbatson.com/covid-19-tracker/

42. Schoenenberger C. COVID-19 Global Cases - Open Source Version [Internet]. 2020 [cited 2020 Mar 30]. Available from:

https://chschoenenberger.shinyapps.io/covid19_dashboard/

43. COVID-19 Dashboard [Internet]. 2020 [cited 2020 Mar 30]. Available from: https://trekhleb.github.io/covid-19/

44. Kamel Boulos MN, Geraghty EM. Geographical tracking and mapping of coronavirus disease COVID-19/severe acute respiratory syndrome coronavirus 2 (SARS-CoV-2) epidemic and associated events around the world: how 21 st century GIS technologies are supporting the global fight against outbr. International journal of health geographics. 2020.

45. Snow J. On the pathology and mode of communication of cholera. London Med Gaz (or J Pract Med. 1849;

46. Pan X-B. Application of personal-oriented digital technology in preventing transmission of COVID-19, China. Irish J Med Sci (1971 -). 2020 ;

47. Bell DM, Aguilera X, Anderson R, Bitar D, Cetron M, Simone P, et al. Public health interventions and SARS spread, 2003. Emerging Infectious Diseases. 2004.

48. Eysenbach G. SARS and population health technology. Journal of Medical Internet Research. 2003.

49. Watson I, S J. Coronavirus mobile apps are surging in popularity in South Korea. 2020.

50. Gruteser M, Liu X. Protecting Privacy in Continuous Location-Tracking Applications. IEEE Secur Priv. 2004;

51. World Health Organization. Mobile health (mHealth) for tobacco control [Internet]. 2016 [cited 2020 Apr 1]. Available from: https://www.who.int/tobacco/mhealth/en/

52. Urban JM, Hoofnagle CJ, Li S. Mobile Phones and Privacy. SSRN Electron J. 2012;

53. S. Bhuyan S, Kim H, Isehunwa O0, Kumar N, Bhatt J, Wyant DK, et al. Privacy and security issues in mobile health: Current research and future directions. Health Policy and Technology. 2017.

54. Adhikari R, Richards D, Scott K. Security and privacy issues related to the use of mobile health apps. In: Proceedings of the 25th Australasian Conference on Information Systems, ACIS 2014. 2014.

55. Computer Laboratory Systems Research Group. Computer Laboratory FluPhone Project [Internet]. 2011. Available from:

https://www.cl.cam.ac.uk/research/srg/netos/projects/archive/fluphone2/

\section{Appendices}

\section{Appendix A}

Table 5. COVID-19 specific features of website applications and dashboards. While these websites and dashboards were not included in our analysis, it is important to highlight mobile technologies available for COVID-19 to date, and further explored in the discussion. Applications which include a specific feature are denoted by an " $\mathrm{X}$ " in the appropriate column. *Symptom management \& sharing is defined as documenting and sharing symptoms with healthcare professionals, and family members. 


\begin{tabular}{|c|c|c|c|c|c|c|c|c|c|}
\hline ures & Description & $\begin{array}{l}\text { Targeted } \\
\text { Country }\end{array}$ & $\begin{array}{l}\text { Live } \\
\text { tracking }\end{array}$ & $\begin{array}{l}\text { News } \\
\text { updates }\end{array}$ & $\begin{array}{l}\text { Statistic } \\
\text { counter }\end{array}$ & $\begin{array}{l}\text { Symptom } \\
\text { screening }\end{array}$ & $\begin{array}{l}\text { Symptom } \\
\text { management } \\
\& \text { sharing* }\end{array}$ & $\begin{array}{l}\text { Information } \\
\text { on next } \\
\text { steps }\end{array}$ & $\begin{array}{l}\text { Information } \\
\text { on } \\
\text { assessment } \\
\text { centres }\end{array}$ \\
\hline ation & & & & & & & & & \\
\hline $\begin{array}{l}\text { S } \\
\text {-19 } \\
\text { ing }\end{array}$ & $\begin{array}{l}\text { Allows users to } \\
\text { screen themselves } \\
\text { for COVID-19 } \\
\text { symptoms and } \\
\text { receive notifications } \\
\text { from the Centre for } \\
\text { Disease Control and } \\
\text { Prevention } \\
\end{array}$ & Worldwide & & & & $\mathrm{X}$ & & $\mathrm{X}$ & \\
\hline iVirus & $\begin{array}{l}\text { An interactive map } \\
\text { that allows tracking } \\
\text { of the spread of } \\
\text { COVID-19, view } \\
\text { stats, and check } \\
\text { affected regions in } \\
\text { real time. } \\
\end{array}$ & Worldwide & $\mathrm{X}$ & $\mathrm{X}$ & $\mathrm{X}$ & & & & \\
\hline $\begin{array}{l}9 \\
\text { avirus) } \\
3\end{array}$ & \begin{tabular}{|l|} 
Web-based \\
application that \\
allows user to check \\
global statistics, \\
latest news, and \\
complete self- \\
assessment. \\
\end{tabular} & Canada & $\mathrm{X}$ & $\mathrm{X}$ & $\mathrm{X}$ & $\mathrm{X}$ & & & \\
\hline ie & \begin{tabular}{|l} 
Web-based \\
application that \\
allows user to \\
create an account, \\
complete COVID-19 \\
self-assessment, get \\
tested and receive \\
results through the \\
application. \\
\end{tabular} & \begin{tabular}{|l} 
USA \\
(California)
\end{tabular} & & & & $\mathrm{X}$ & $\mathrm{X}$ & $\mathrm{X}$ & $\mathrm{X}$ \\
\hline near & $\begin{array}{l}\text { Web-based } \\
\text { application that } \\
\text { allows users to } \\
\text { contribute to the } \\
\text { health status and } \\
\text { tracking of COVID- } \\
19 \text { daily. By } \\
\text { inputting personal } \\
\text { symptoms, duration, } \\
\text { quarantine/isolation } \\
\text { status, exposure to } \\
\text { COVID-19, zip-code, } \\
\text { and birthdate, } \\
\text { participants } \\
\text { contribute to } \\
\text { general knowledge } \\
\text { to build a } \\
\text { distribution map. } \\
\text { The application also } \\
\text { tracks COVID-19 } \\
\text { activity in the US } \\
\text { and highlights the } \\
\text { number of cases in } \\
\text { the past } 2 \text { weeks in } \\
\text { the US. } \\
\end{array}$ & USA & & $\mathrm{X}$ & $\mathrm{X}$ & & $\mathrm{X}$ & & \\
\hline $\begin{array}{l}\mathrm{gg} \\
\text { ivirus } \\
19\end{array}$ & \begin{tabular}{|l} 
This application \\
provides global \\
information on \\
number of \\
confirmed cases \\
and deaths, daily. \\
This web-based \\
application includes \\
interactive mapping \\
to visualize the \\
global distribution \\
of the COVID-19 \\
outbreak. \\
\end{tabular} & Worldwide & & & & $\mathrm{X}$ & & & \\
\hline \multicolumn{10}{|l|}{ oards } \\
\hline $\begin{array}{l}-19 \\
r \\
\text { jard }\end{array}$ & \begin{tabular}{|l|} 
This application \\
provides a \\
dashboard of \\
confirmed and \\
recovered cases by \\
country, and total \\
numbers of deaths, \\
and critical cases. \\
Visualization of
\end{tabular} & Worldwide & & & $\mathrm{X}$ & & & & \\
\hline
\end{tabular}




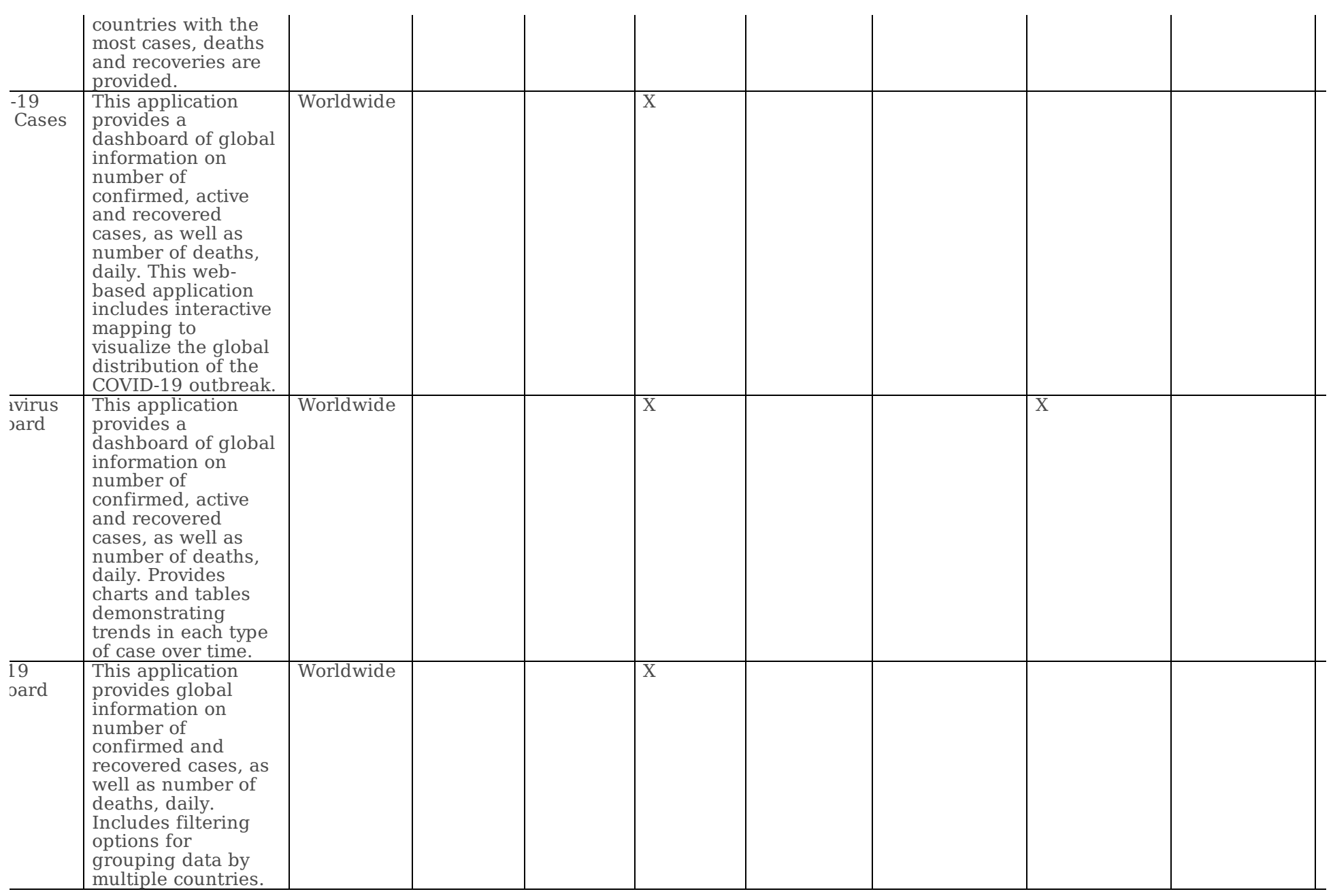

\section{Appendix B}

Table 6. Two unique references obtained through grey literature search of Google

These applications were not available for download within Canada, and a thematic description could only be provided.

\begin{tabular}{|c|c|}
\hline Application & Description \\
\hline FluPhone [55] & $\begin{array}{l}\text { Created by the University of Cambridge and University of Liverpool following the SARS epidemic in } 2003 \text {, the mobile app is } \\
\text { currently being investigated to determine how many people come into contact with each other through their mobile devices. } \\
\text { The app tracks interactions using Bluetooth technology, to understand how individuals can be exposed to disease and } \\
\text { contribute to spread. }\end{array}$ \\
\hline $\begin{array}{l}\text { Corona } 100 \mathrm{~m} \\
{[49]}\end{array}$ & $\begin{array}{l}\text { Mobile app that notifies individuals in South Korea on where COVID-19 patients have been and how close they currently are, } \\
\text { when within a } 100 \mathrm{~m} \text { radius. This central tracking app is based on SARS applications that emerged following the } 2003 \\
\text { outbreak, and utilizes Bluetooth technology. }\end{array}$ \\
\hline
\end{tabular}

\section{Supplementary Files}

This is a list of supplementary files associated with this preprint. Click to download.

- PRISMAScRCOVID202004171.pdf

- SupplementaryFilesDataExtractionTables.pdf 